\title{
Influenza, 1918
}

The worst recorded influenza outbreak took place in 1918, when my uncle, Dr Jules S Martin, was a young doctor in the Royal Army Medical Corps in Mozambique. This letter from his commanding officer gives an insight into the horror of the experience

\section{Iain H Wilson \\ joint medical director and consultant anaesthetist \\ Royal Devon and Exeter Hospital, Exeter EX2 5DW iain.wilson5@ virgin.net}

BMJ 2005;331:1536
RAMC Mess,

Aldershot,

9th April 1919

Dear Mr Martin,

I arrived at Aldershot this morning, and got your letter dated the $30^{\text {th }}$ of last month. The unit I was in charge of in East Africa came home on $12^{\text {th }}$ March, and since then I have been on leave. I intended to write to you about your son, as soon as I settled down.

We had a dreadful experience, when influenza broke out in Port Amelia [Mozambique]. As well as your son, eleven of the hospital staff died, and a large number of the white and Indian Garrison.

Your son did not get infected by "Ingle," who was in his tent, but I think some time after Ingle was admitted, and undoubtedly contracted it while doing his medical duties in his wards. At the time I think he was in charge of some Indian wards. I saw him myself every day during the time he was ill, but the day before he died was admitted to hospital myself with the disease.

He did fairly well the first three days, and was quite cheerful about himself, but his temperature remained up quite high, and he suffered from a gastritis, and a good deal of vomiting. About the fifth day or so his right lung became affected, and later the left, and he was obviously very ill, but in no pain at all. He gradually felt worse, and I think about the $8^{\text {th }}$ day was quite unconscious.

For the day or two before he was obviously suffering from severe poisoning (what we called septic cases of influenza of which unfortunately we had a lot)-and was drowsy and difficult to rouse. During the night of I think the $9^{\text {th }}$ day of his illness he died. As a matter of fact I was lying ill myself in the next tent to him, and could hear in the stillness of the night his rather heavy breathing-and I heard it stop suddenly.

They did not tell me for some days that he had died, being afraid it might upset me I suppose, and get worse myself, but I knew perfectly well. You can be perfectly assured that he suffered no pain whatsoever, and his doctor, and sister who

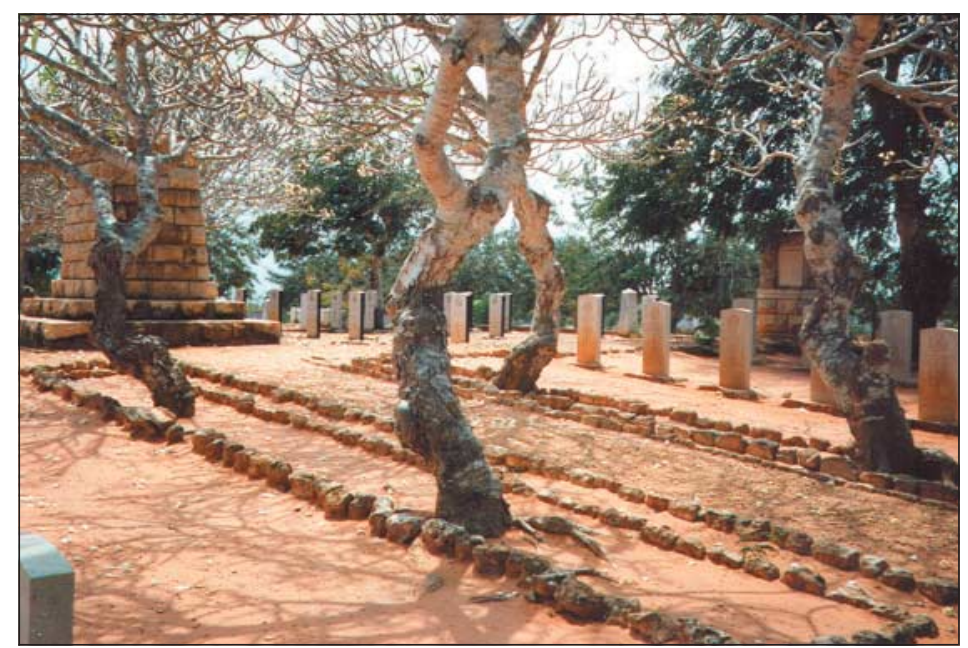

Pemba Cemetery, Mozambique were looking after him, and incidentally myself, could not have been kinder. Owing to the onset of drowsiness and unconsciousness several days before, he could not leave any messages.

I sympathise deeply with yourself and Mrs Martin over your sad loss, as your son was a splendid lad, and had a brilliant future before him. He was a very capable doctor, and I could always rely on him to do his work thoroughly. For some time before the epidemic broke out, he was working in the laboratory of the hospital with Capt Garrow RAMC, who was a great friend of his, and is now in Dar es Salaam, if you should wish to write to him-or was when I left.

Five of the Medical Officers and myself contracted the disease, and 65 of the nursing orderlies, and all the sisters except two. The gloom cast over the whole place was appalling, as the men felt that they had managed to exist through the years of the war, and then when the war was over, it seemed so hard to fall the victim of such a disease. Your boy seemed very unfortunate; when he was working under me he had a good deal of fever, and then later got what I considered was typhoid. But latterly he was very strong and healthy, and was playing cricket, and football with the best.

And that was my experience of the epidemic; the older men, and men who were debilitated with fever, seemed to escape; and the young athletic fellows died. The hospital football team was practically wiped out - I think 5 died. The doctor "Ingle" your son mentioned very nearly died; was off his head, and with double pneumonia for two weeks - and the other three men were sent home on a hospital ship. I got off fairly lightly.

After I came out of hospital I saw all your son's kit, and effects packed up, and you should be receiving them soon. Among his effects are a collection of "Blood slides" of various diseases he had taken, that I think he intended to hand over to the laboratory he had been working at in Glasgow as a student. Perhaps you might send them for him.

You can have no idea of the depression your boy's death caused among his fellow officers-no one could bear to speak of it for weeks after, as we were all so fond of him. He was always cheery and bright; and full of enthusiasm for his profession, and undoubtedly had a brilliant career in front of him in Pathological work, if he had gone on with it, as he told me he had intended. I have complete notes of his case, and temperature chart among my papers, which have been sent to my base in London. But will collect them when I get a chance, and could then give you the full details.

Assuring you of my deepest sympathy.

Believe me.

Yours sincerely

\section{J A Mansfield [Hospital Commander]}

An additional letter came from the Padre:

Yesterday a cement cross was put up by the R.E. over the grave bearing the words "Captain J S Martin, R.A.M.C. Died $15^{\text {th }}$ November 1918. Aged 25 years". A photograph of this is being taken and sent on to you. More than $5 \%$ of our European Garrison, and 10\% of the Hospital Unit, have died.

S Legrove-Smith 